\title{
Low-cost Air Purifier Prototype using a Ventilating Fan and Pump against COVID-19 and Haze Pollution
}

\author{
Arnon Jumlongkul ${ }^{1^{*}}$ \\ ${ }^{1}$ School of Medicine, Mae Fah Luang University, Chiang Rai, Thailand \\ * Correspondence: Arnon Jumlongkul \\ arnon.jum@mfu.ac.th
}

Keywords: air filtration, air purifier, COVID-19, haze, HEPA filter, particulate matter.

\begin{abstract}
Purpose: This study aimed to focus on the design and development of low-cost DIY air purifiers, using a ventilating fan, air pump, water pump, and an ultrasonic generator, with regard to filtration efficacy and also cost-effectiveness that can be used during the COVID-19 pandemic and haze pollution.
\end{abstract}

Methods: Six types of household air purifiers, incorporating a HEPA filter, a HEPA filter \& electrostatic fiber, an air pump, an air pump \& ultrasonic wave, a water pump, and a water pump $\&$ ultrasonic wave, were fabricated. The amount of particulate matter (PM) and $\mathrm{CO}_{2}$ levels were recorded at $0,10,20,30$, and $60 \mathrm{~min}$, then, repeated 3 times. After $10 \mathrm{~min}$ of the $3^{\text {rd }}$ experiment of each study, the last measurement of air pollution would be recorded.

Results: At $60 \mathrm{~min}$, the HEPA filter \& electrostatic fiber showed the best performance regarding reduction of $\mathrm{PM}$ and $\mathrm{CO}_{2}$ levels. The highest $\mathrm{PM}$ reduction rate had occurred at $30 \mathrm{~min}$ using an air pump procedure (99.330 to $100 \%$ ). The $\mathrm{CO}_{2}$ levels of all experiments had fluctuated at different times. After 10 min of a closed machine, HEPA filter \& electrostatic fiber revealed the highest rate of PM elevation, while PM levels of all water-based purifier systems were decreased. A water pump and air pump were the cheapest air cleaners, when taking into account maintenance expenses and electricity charges.

Conclusion: An air pump is the optimum method for reducing particulate matter at minimum cost but without the benefit of reduced humidity, while the HEPA filter \& electrostatic fiber is the best system to decrease PM levels, but this requires an enclosed structure at the inlet to prevent dust coming back into the room. As filtration efficiency is increased by the use of filters \& electrostatic fiber mechanisms, the more expensive the system becomes.

\section{Introduction}

Air pollution has become one of the global health hazards in the $21^{\text {st }}$ century. From the report of the World Health Organization, 4.2 million premature deaths globally every year have been linked to outdoor air pollution. The major causes of death included $43 \%$ chronic obstructive pulmonary disease, $29 \%$ lung cancer, $25 \%$ ischemic heart disease, $24 \%$ stroke, and $17 \%$ acute lower respiratory infection, respectively. One of the main causes of ambient air pollution is particulate 
matter, especially that which is less than 2.5 microns as well as particles of 10 microns in diameter (PM2.5 and PM10). PM can penetrate the lung and enter the bloodstream, eventually destroying many respiratory, cardiovascular, and cerebrovascular functions [1]. Over the period 1960 to 2009, the mean population-weighted PM2.5 concentrations were found to have increased by 38\%, mainly noted in China and India, which attributed to global death increase by 89 to $124 \%$ while PM2.5 concentration trends were reduced in Europe and the United States [2]. Thailand's northern region, especially in Chiang Mai and Chiang Rai Provinces, which are the northern frontier of Thailand with Laos and Myanmar, has been facing increasing haze pollution over the past decade. Haze pollution usually occurs during the dry season, from January to May, peaking in March every year. This problem reached a crisis when in March 2019, for several days, the PM2.5 and PM10 levels were higher than the national standard of $25 \mu \mathrm{g} \mathrm{m}^{-3}$ and $50 \mu \mathrm{g} \mathrm{m}^{-3}$. Even though the Thai government has introduced laws and attempted to manage haze and forest fires since 2006, air pollution has been a persisting problem $[3,4]$.

The composition of air pollution varies according to the origin, emission rate, and environment. The main components of particulate matter include nitrates, sulfates, endotoxins, polycyclic aromatic hydrocarbons, iron, nickel, copper, zinc, etc. Coarse particles (PM10) derive from both industrial and natural sources that cannot permeate beyond the upper bronchus while fine (PM2.5) as well as ultrafine (PM0.1) particles, which are generated from the combustion of fuels, may affect the lower part of the airway. Therefore, both acute and chronic PM exposures can be expected to promote cardiovascular hazards, including, heart failure, ischemic stroke, and also ischemic heart disease [5]. To reduce the levels of PM, the use of low-sulfur diesel fuel and biofuel to replace oil-based fuel, increased management of sources of combustion and industrial activity, and the creation of pollution control legislation, are applicable [6]. However, the implementation of public policymaking of haze management is problematic. When considering the COVID-19 pandemic, coughing and sneezing can generate respiratory droplets, which are usually larger than $5 \mu \mathrm{m}$, and are the most respiratory infection transmission while particles, measuring $5 \mu \mathrm{g}$ in diameter or smaller, can remain airborne. Data revealed that viruses SARS-CoV-2 can be transmitted by both small and large aerosols and it has been detected in the air within many hospitals. Therefore, haze problems cannot separate from COVID-19 spreading absolutely [7].

The key attribute of any indoor air filtration system is a balance of adequate ventilation, filtration efficacy, and reasonable cost-effective maintenance, without adverse airflow and efficiency effects. A multi-layer air filtration system, composed of a pre-filter, carbon filter, antibacterial filter, and also a high-efficiency particulate air (HEPA) filter, has been the usual solution [8]. However, this technique consists of many components, which are not amenable to simple construction methods. In commercial portable HEPA filter air cleaners, the filtration efficacy is highly effective against diesel combustion, which creates many sizes of small particles [9]. Therefore, a compact air cleaner can be amalgamated with a ventilating fan without great difficulty. A solution that has commonly been applied for household smog eradication is based on a commercial household vacuum cleaner, which has a water-based cleaning system, and which significantly reduced both PM concentrations (PM1, PM2.5, and PM10) and particle numbers. However, the main drawback of a traditional household vacuum cleaner is that dust can reduce the airflow rate or even damage the filter [10]. To enhance the household air filter performance, 
ionizer-assisted air filtration can be applied. All submicron, ultrafine particles, fine particles, as well as coarse particles are then removed from the environment. So ionization should be used with an air filter to improve the filtration efficiency. A byproduct of the ionizer air purifier, which can lead to damage of the respiratory system, is ozone. To solve this problem, carbon fiber ionizers were added for ozone reduction [11]. That means this total system cannot be fabricated without mechanical expertise.

In the setting of low- and middle-income countries, there is a lack of novel technologies as well as experts to provide a high-performance household air purifier, these same areas are those most affected by the ongoing haze crisis and also COVID-19 spreading. An alternative strategy, that can provide low-cost health hazard protection, is to develop a common do-it-yourself (DIY) air purifier prototype and sharing the design. However, a suitable DIY air purifier model is still open to question. Therefore, this study attempted to focus on the design and fabrication of a low-cost DIY air purifier, using a ventilating fan, air pump, water pump, and also an ultrasonic generator and then to evaluate the filtration efficacy and also cost-effectiveness, to create a prototype of a low-cost DIY air purifier, easily constructed using simple methods.

\section{Material and Methods}

Six types of household air purifiers, which were set at a similar initial cost, were fabricated and tested. To promote a cost-benefit analysis, all inventories and labor costs were limited to not exceed than 5,000 Thai baht (THB) for each prototype. Some techniques and testing procedures are shown below.

\subsection{Machinery design}

The essential functions of the HEPA filter rely on 3 parts, firstly, outer filters, which work like sieves, that can prevent coarse particles entering to damage the filtration system. Secondly, a mat of dense fibers that are designed to trap either fine or ultrafine particles. Finally, the inner part of the filter that can catch air particles, using direct contact, when clouds of dust flow at high speeds, while at the same time some particles tend to attach the filter randomly at lower airspeeds according to Brownian movement [12]. Therefore, two air purifier prototypes were made using a HEPA filter and a ventilating fan. An ultra-dense $\mathrm{H} 11$-grade $360^{\circ}$ cylindrical triple-filter including, a primary filter, HEPA filter, an activated carbon filter, was amalgamated with a ventilating fan $0.04 \mathrm{~A} 8 \mathrm{~W} 220 \mathrm{~V} 50 \mathrm{~Hz}$, output $0.480 \mathrm{~m}^{3} \mathrm{~min}^{-1} \mathrm{~W}^{-1}$ to ensure that the airflow rate could produce contact between the particles and the HEPA filter. This dual device was positioned to be the main component of the air purifier. The HEPA filter with a ventilating fan prototype is shown in Figure 1. One technique that has been used as a component of air filtration processes is an electret polypropylene (PP) filter, which is combined with charge enhancers, such as magnesium stearate (MgSt), titanium dioxide $\left(\mathrm{TiO}_{2}\right)$, lithium niobate $\left(\mathrm{LiNbO}_{3}\right)$, silicon dioxide $\left(\mathrm{SiO}_{2}\right)$, nanoscale graphite platelets, barium titanate $\left(\mathrm{BaTiO}_{3}\right)$, etc $[13,14]$. Therefore, another air cleaner model, using a HEPA filter with a ventilating fan was linked to an electrostatic air conditioner filter, made of PP fiber, in a separate enclosure. The HEPA filter with an electrostatic fiber prototype is shown in Figure 2. 
The other four air purifier prototypes were designed to work without the use of a HEPA filter. An aquarium air pump $220 \mathrm{~V} 50 \mathrm{~Hz} 25 \mathrm{~W}$, maximum output $55 \mathrm{~L} \mathrm{~min}^{-1}$ was mounted with a glass chamber $\left(\mathrm{L} \times \mathrm{W} \times \mathrm{H}=0.35 \mathrm{~m} \times 0.17 \mathrm{~m} \times 0.21 \mathrm{~m}=0.0125 \mathrm{~m}^{3}\right)$ and filled with $9 \mathrm{~L}$ freshwater. Dirty air is forced through the water, producing air bubbles in the water. The bubble dynamics, including bubble size, shape, and velocity, are influenced by buoyancy, viscosity, and surface tension $[15,16]$. Ideally, the contaminants should be contained within the water, returning only fresh air to the environment. However, large bubbles usually bring the contaminants to the surface of the water and back into the ambient air again. One technique, which can reduce the size of bubble formation, is the use of emulsions containing hydrophobic particles, also called "antifoams". Some additional ingredients may be used as antifoams, for example, linseed oil, phenyl ether, milk, polyamides, kerosene, amyl alcohol, trimethylcyclohexanol, etc [17]. However, after the air passes through the water, it should return to the environment without being filtered again. This means that chemicals should not be added to the water, to ensure that an air purifier returns only fresh air back to the environment. Therefore, as an alternative, the surface of the water was covered with only a polyurethane sponge to prevent larger air bubbles returning to the environment. The air pump method, compared to the HEPA filter amalgamated with a ventilating fan method, is shown in Figure 3.

To compare the filtrate efficiency between an air pump and a water pump, an aquarium submersible pump AC $220 \mathrm{~V} 50 \mathrm{~Hz} 25 \mathrm{~W}$, maximum pump head $1.5 \mathrm{~m}$, maximum flow rate 1,500 $\mathrm{L} \mathrm{hr}^{-1}$, was used for this purpose. This uses the Venturi effect to make a water vacuum pump, which is the result of Bernoulli's principle in fluid dynamics. When the speed of fluid is increased as it passes through a pipe, which is suddenly reduced in diameter, the accelerated energy also creates a vacuum effect that can be used for the air suction [18]. Other filtration components, except a water pump, were set as the air pump technique.

The last two methods, which were based on an air compressor as well as a water vacuum pump, were incorporated with an ultrasonic wave generator. The acoustic agglomeration technique, which is generated by sound waves, showed a high efficiency of PM2.5 removal [19]. In general, ultrasonic mist maker testing has usually been carried out on simulated fog and fire suppression systems [20]. However, the study of the correlation of ultrasonic waves and water-based air purifier systems is minimal. Therefore, an aquarium mist maker $220 \mathrm{~V} 50 \mathrm{~Hz} 25 \mathrm{~W}$ was used for these experiments. It was positioned beneath a polyurethane sponge to prevent mist formation as well as pseudo-hazing. The test of the water pump technique compared with the water pump with the ultrasonic wave technique is shown in Figure 4.

\subsection{Air pollution tests}

Closed air within the PVC box $\left(\mathrm{L} \times \mathrm{W} \times \mathrm{H}=0.45 \mathrm{~m} \times 0.45 \mathrm{~m} \times 0.50 \mathrm{~m}=0.10125 \mathrm{~m}^{3}\right)$ was used to simulate room air pollution. The amount of haze at $0,10,20,30$, and $60 \mathrm{~min}$ was recorded during air purifier prototype testing. The average percentage of haze was calculated 3 times for each experiment. After the $3^{\text {rd }}$ experiment of each study, and the air purifier had been switched off $10 \mathrm{~min}$, then, the last measurement of air pollution within the box was conducted. 
Two instruments were used for this study, firstly, the Portable Particle Counter Model 9310 TSI AeroTrak ${ }^{\circledR}$ for cleanroom measurement, was used for calculating the number of particle sizes of $0.3,0.5,1.0,3.0,5.0$, and $10 \mu \mathrm{m}$ (particle $\mathrm{m}^{-3}$ ), respectively. Secondly, Q-Trak ${ }^{\mathrm{TM}}$ Indoor Air Quality Monitor Model 7575, was used for $\mathrm{CO}_{2}$ detection (ppm).

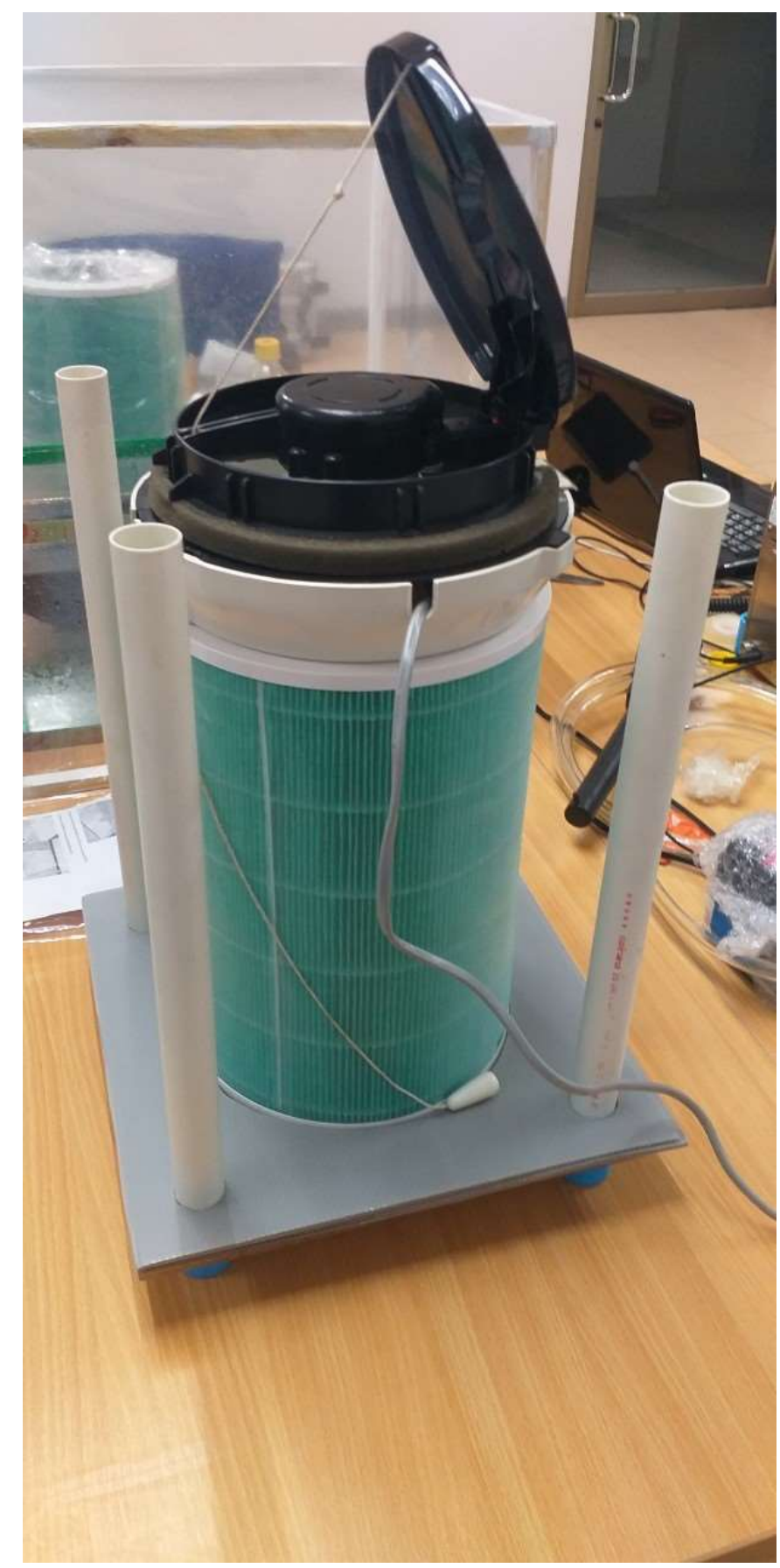

Figure 1. The HEPA filter with a ventilating fan prototype 


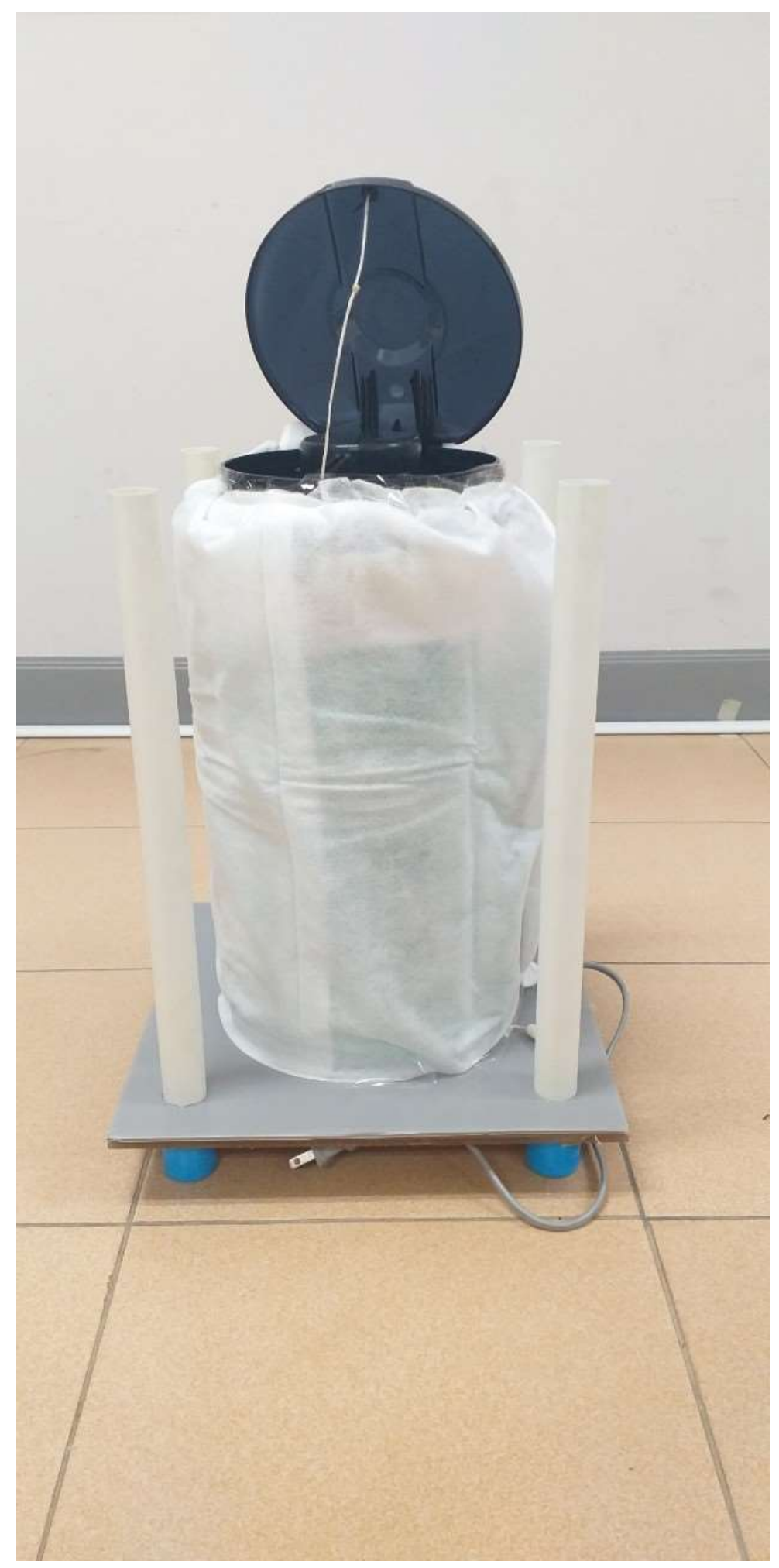

Figure 2. The HEPA filter amalgamated with a ventilating fan and an electrostatic filter prototype 


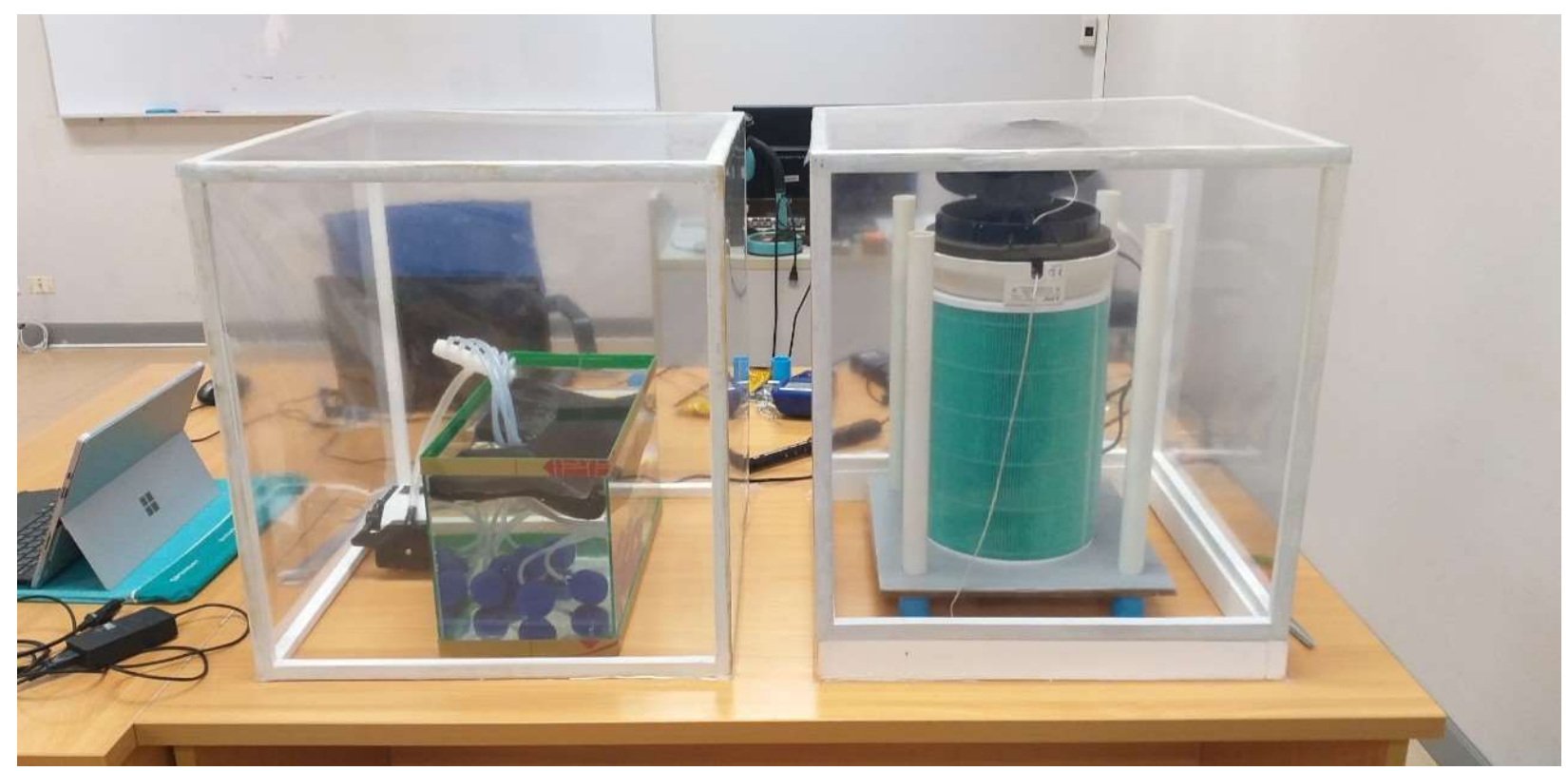

Figure 3. The test of the air pump technique (left) and the HEPA filter with a ventilating fan technique (right) within PVC boxes

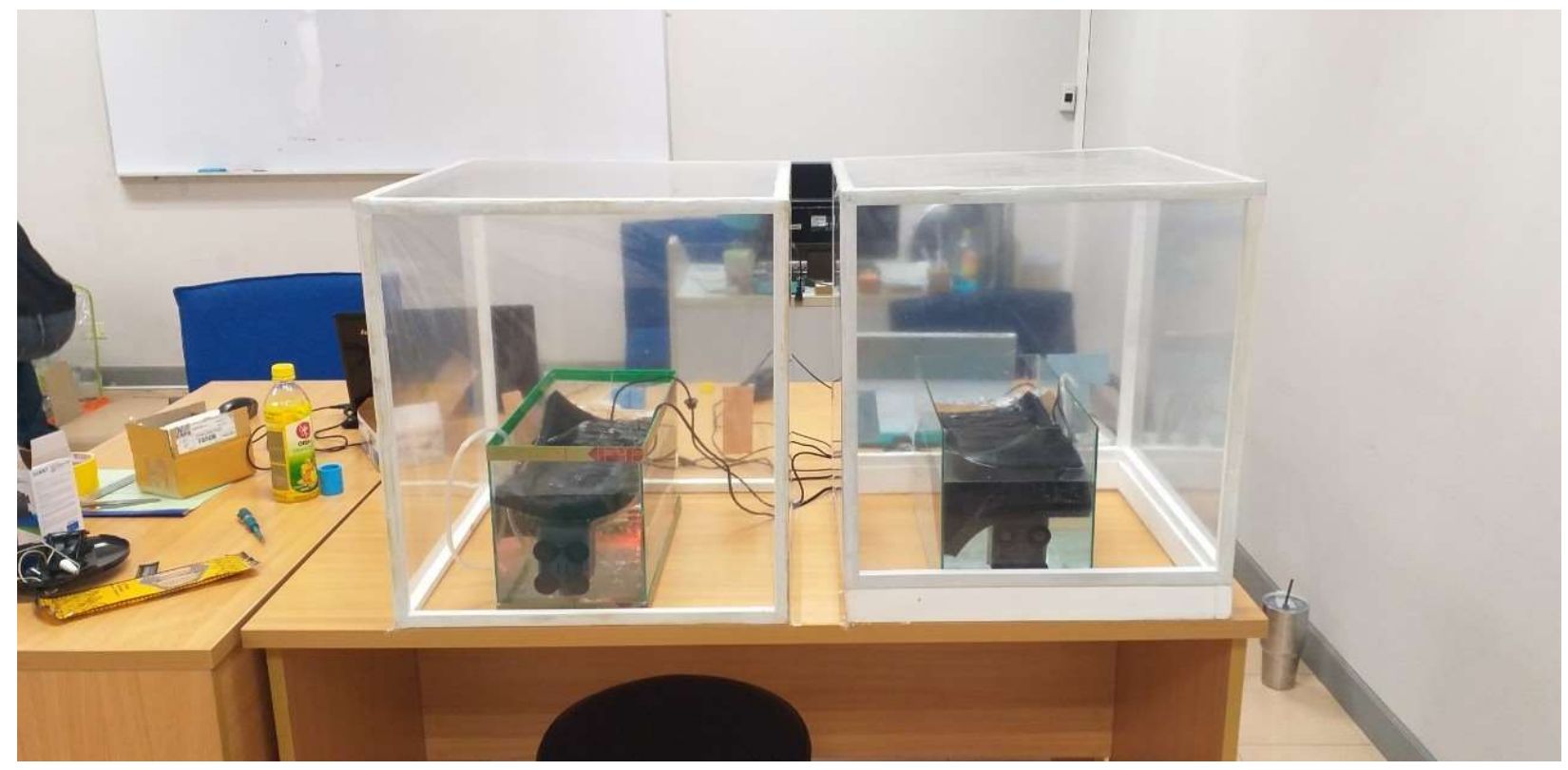

Figure 4. The test of the water pump with the ultrasonic wave technique, which showed a red light from the mist maker (left), and the water pump technique (right) within PVC boxes 


\section{Results}

Over 18 experiments, each air purifier prototype was tested 3 times. The results of filtration efficacy and cost-effectiveness among each air purifier prototype are shown as follows.

\subsection{Particulate matter and $\mathrm{CO}_{2}$ levels}

In Table 1, at 60 min air treatment, an air purifier using a HEPA filter amalgamated with electrostatic fiber showed the best performance in reducing any type of particulate matter $(92.727$ to $95.411 \%$ ) as well as a $4.335 \%$ reduction in $\mathrm{CO}_{2}$ levels. In the group of air purifiers using waterbased air treatment, an added air pump technique had the highest efficiency in decreasing particulate matter. However, the trend of PM levels, as shown in Figure 5, revealed that the level of particulate matter, which was treated only by an air pump technique, also significantly dropped after 30 min of treatment. In Table 2, three types of air purifiers, with the best reduction of the levels of particulate matter, included an air pump technique $(99.330$ to $100 \%)$ at 30 min air treatment, HEPA filter \& electrostatic fiber $(92.727$ to $95.411 \%)$ at $60 \mathrm{~min}$ air treatment, and HEPA filter (0 to $91.003 \%$ ) at $30 \mathrm{~min}$ air treatment, respectively. After $30 \mathrm{~min}$ air treatment using all water-based purifier systems, a great amount of vapor had appeared, contrasting with both HEPA filter-based techniques, which did not produce vapor. The extent of vapor appearance is shown in Figure 6. Figure 7 shows the $\mathrm{CO}_{2}$ levels, in the range of 416 to 531.667 ppm, which fluctuated at different times during all the tests.

At the $3^{\text {rd }}$ experiment of each air purifier prototype, the differences in air pollution comparing between $60 \mathrm{~min}$ air treatment and $10 \mathrm{~min}$ after the process finished is shown in Table 3. HEPA filter \& electrostatic fiber methods revealed the highest rate of PM elevation, from 1,461.180 to 4,800\% in PM0.3, PM0.5, PM1.0, and PM3.0 levels, followed by the HEPA filter procedure, whilst all water-based purifier systems showed a decrease of particulate matter levels. Focusing on the HEPA filter technique, in which PM10 was completely eradicated at 60 min air treatment, this showed a return of 35.336 particles $\mathrm{m}^{-3}$, made up of 494 and 35.336 particles $\mathrm{m}^{-3}$ of PM5.0 and PM10, in the HEPA filter \& electrostatic fiber system, respectively. The $\mathrm{CO}_{2}$ levels during all experiments did not vary by more than $4 \%$. 


\begin{tabular}{|c|c|c|c|c|c|c|c|}
\hline \multirow{2}{*}{ Prototype } & \multicolumn{7}{|c|}{ Percentage differentiation of air pollution at $60 \mathrm{~min}$} \\
\hline & PM0.3 & PM0.5 & PM1.0 & PM3.00 & PM5.0 & PM10 & $\mathrm{CO}_{2}$ \\
\hline \multirow{2}{*}{$\begin{array}{l}\text { HEPA filter } \\
\text { HEPA \& } \\
\text { electrostatic } \\
\text { fiber }\end{array}$} & -80.966 & -81.808 & -76.701 & -78.218 & -78.788 & -100 & +8.458 \\
\hline & -94.095 & -94.720 & -95.096 & -95.411 & -92.727 & $-*$ & -4.335 \\
\hline Air pump & -51.785 & -56.917 & -44.293 & +62.150 & +39.256 & 0 & +6.978 \\
\hline wave & +54.173 & +193.833 & +256.894 & +247.060 & +154.656 & -50 & +2.083 \\
\hline $\begin{array}{l}\text { Water } \\
\text { pump }\end{array}$ & +58.410 & +119.310 & +158.278 & +199.132 & +181.949 & -100 & -3.815 \\
\hline Water pump & & & & & & & \\
\hline \& ultrasonic & & & & & & - & \\
\hline wave & +32.127 & +48.140 & +140.074 & +175.293 & +152.691 & 66.667 & -3.410 \\
\hline
\end{tabular}

Table 1. The percentage differentiation of particulate matter $\left(\right.$ particle $\left.\mathrm{m}^{-3}\right)$ and $\mathrm{CO}_{2}(\mathrm{ppm})$ among 6 types of air purifiers when compared between 0 and 60 min air treatment

\begin{tabular}{|c|c|c|c|c|c|c|}
\hline \multirow{2}{*}{ Prototype } & \multicolumn{6}{|c|}{$\begin{array}{l}\text { Percentage differentiation of the best performance of air } \\
\text { purifiers }\end{array}$} \\
\hline & PM0.3 & PM0.5 & PM1.0 & PM3.00 & PM5.0 & PM10 \\
\hline $\begin{array}{l}30 \text { min HEPA } \\
\text { filter } \\
60 \text { min HEPA }\end{array}$ & -91.003 & -90.936 & -86.499 & -81.683 & -81.818 & 0 \\
\hline $\begin{array}{l}\text { \& electrostatic } \\
\text { fiber } \\
30 \text { min Air } \\
\text { pump }\end{array}$ & -94.095 & -94.720 & -95.096 & -95.411 & -92.727 & -100 \\
\hline
\end{tabular}

Table 2. The percentage differentiation of particulate matter (particle $\mathrm{m}^{-3}$ ) among the best 3 prototypes of air purifiers at the best air pollution-reducing times 


\begin{tabular}{|c|c|c|c|c|c|c|c|}
\hline \multirow{2}{*}{ Prototype } & \multicolumn{7}{|c|}{ Percentage differentiation of air pollution after $10 \mathrm{~min}$ process finishing } \\
\hline & PM0.3 & PM0.5 & PM1.0 & PM3.0 & PM5.0 & PM10 & $\mathrm{CO}_{2}$ \\
\hline \multirow{3}{*}{$\begin{array}{l}\text { HEPA filter } \\
\text { HEPA \& } \\
\text { electrostatic } \\
\text { fiber }\end{array}$} & +134.162 & +126.973 & +109.695 & +125.000 & +200 & $+35.336^{*}$ & +0.633 \\
\hline & & & & & & & \\
\hline & +1461.180 & +1607.347 & +2158.696 & +4800.000 & $+494^{*}$ & $+35.336^{*}$ & -2.247 \\
\hline Air pump & -21.339 & -31.982 & -36.464 & -58.130 & 80.882 & -100 & +0.221 \\
\hline $\begin{array}{l}\text { Air pump \& } \\
\text { ultrasonic }\end{array}$ & & & & & t & & \\
\hline wave & -20.537 & -42.334 & -49.051 & -54.799 & 60.145 & 0 & +1.370 \\
\hline Water pump & -8.675 & -21.801 & -40.577 & -63.479 & 66.733 & 0 & -3.862 \\
\hline Water pump & & & & & & & \\
\hline \& ultrasonic & & & & & - & & \\
\hline wave & -9.180 & -21.265 & -36.681 & -53.316 & 74.522 & 0 & -2.614 \\
\hline
\end{tabular}

Table 3. The percentage differentiation of particulate matter $\left(\right.$ particle $\left.\mathrm{m}^{-3}\right)$ and $\mathrm{CO}_{2}(\mathrm{ppm})$ among 6 types of air purifiers at the $3^{\text {rd }}$ experiment comparing with $60 \mathrm{~min}$ air treatment and $10 \mathrm{~min}$ after process completion 


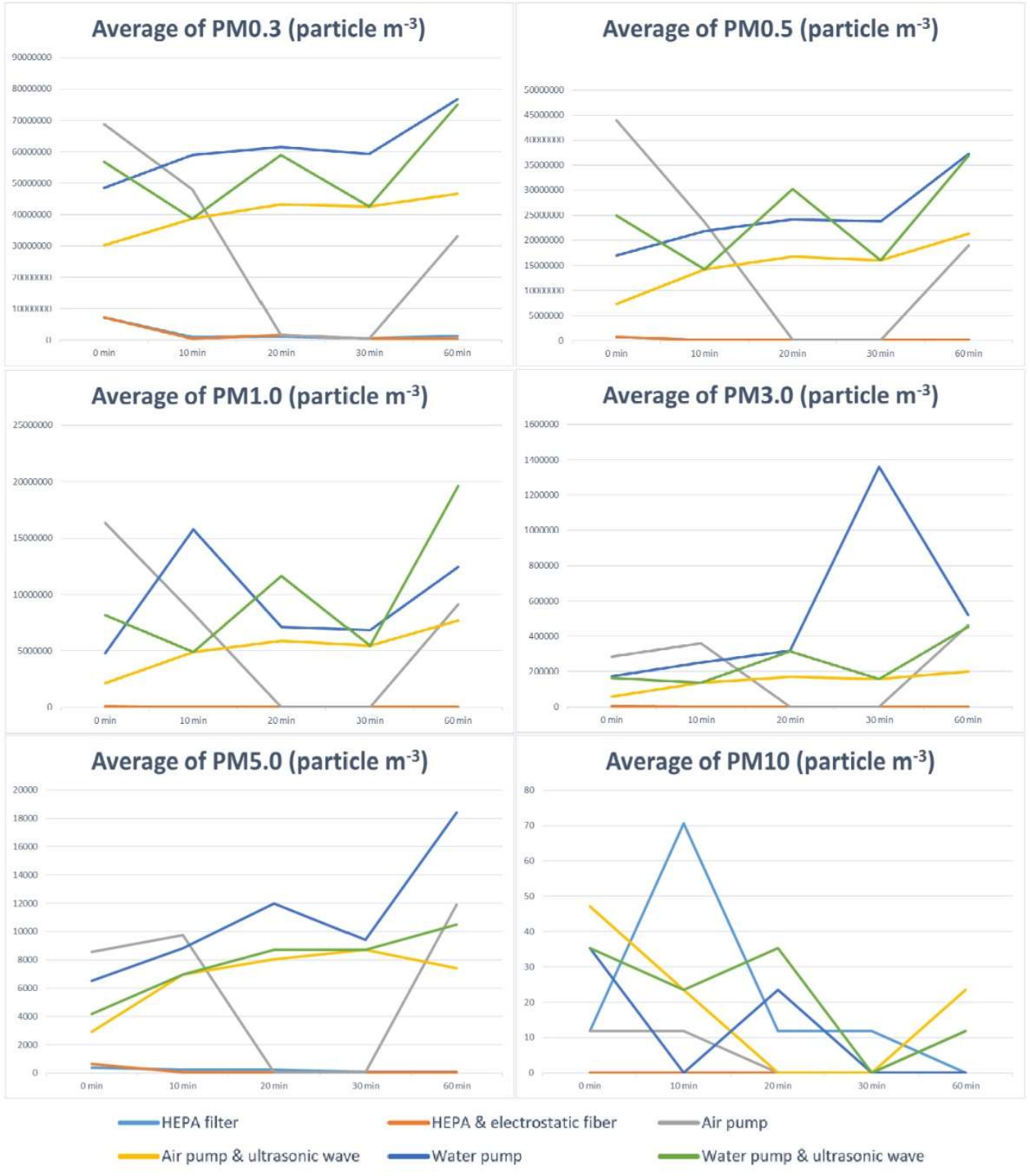

Figure 5. The average number of particle sizes of $0.3,0.5,1.0,3.0,5.0$, and $10 \mu \mathrm{m}\left(\right.$ particle $\mathrm{m}^{-3}$ ) at different times 


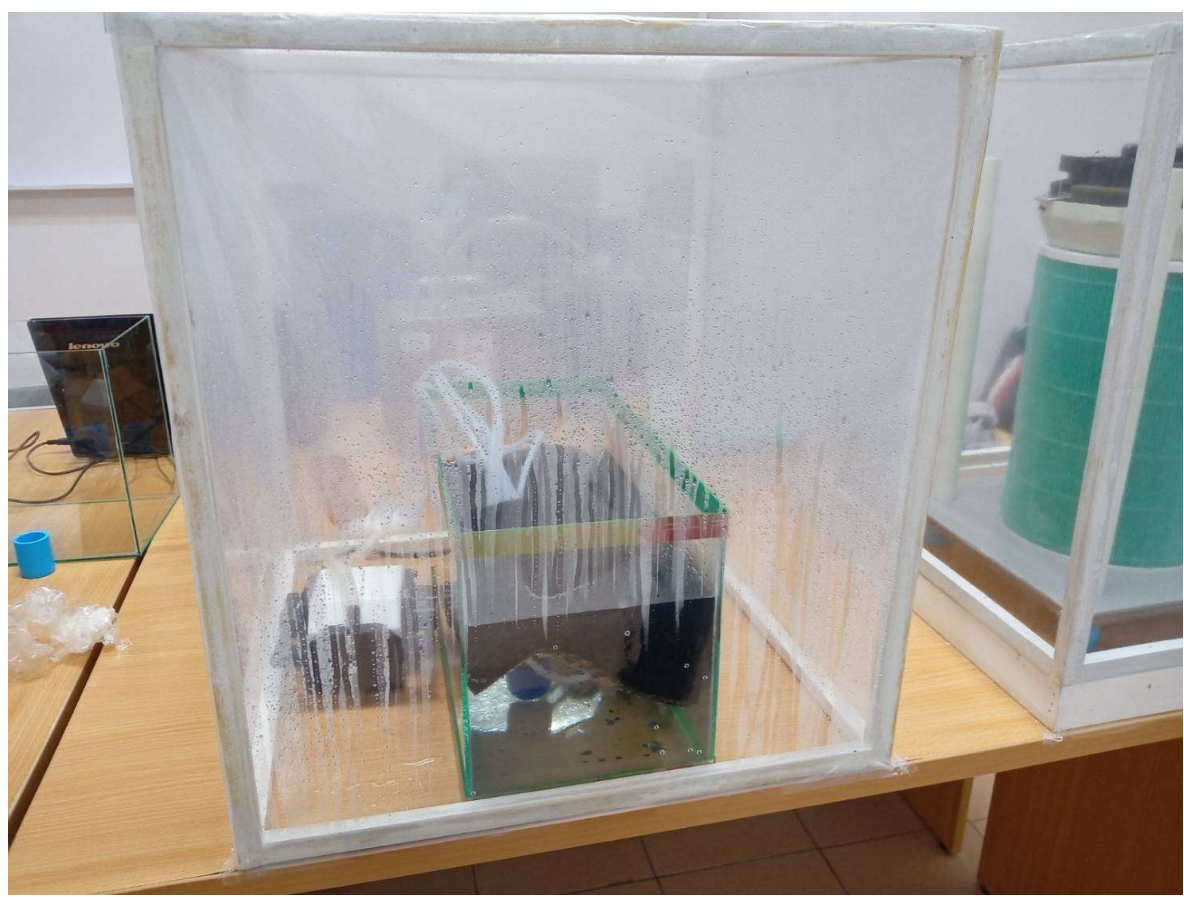

Figure 6. The appearance of vapor within the PVC box that covered the air purifier using an air pump after $30 \mathrm{~min}$ of air treatment

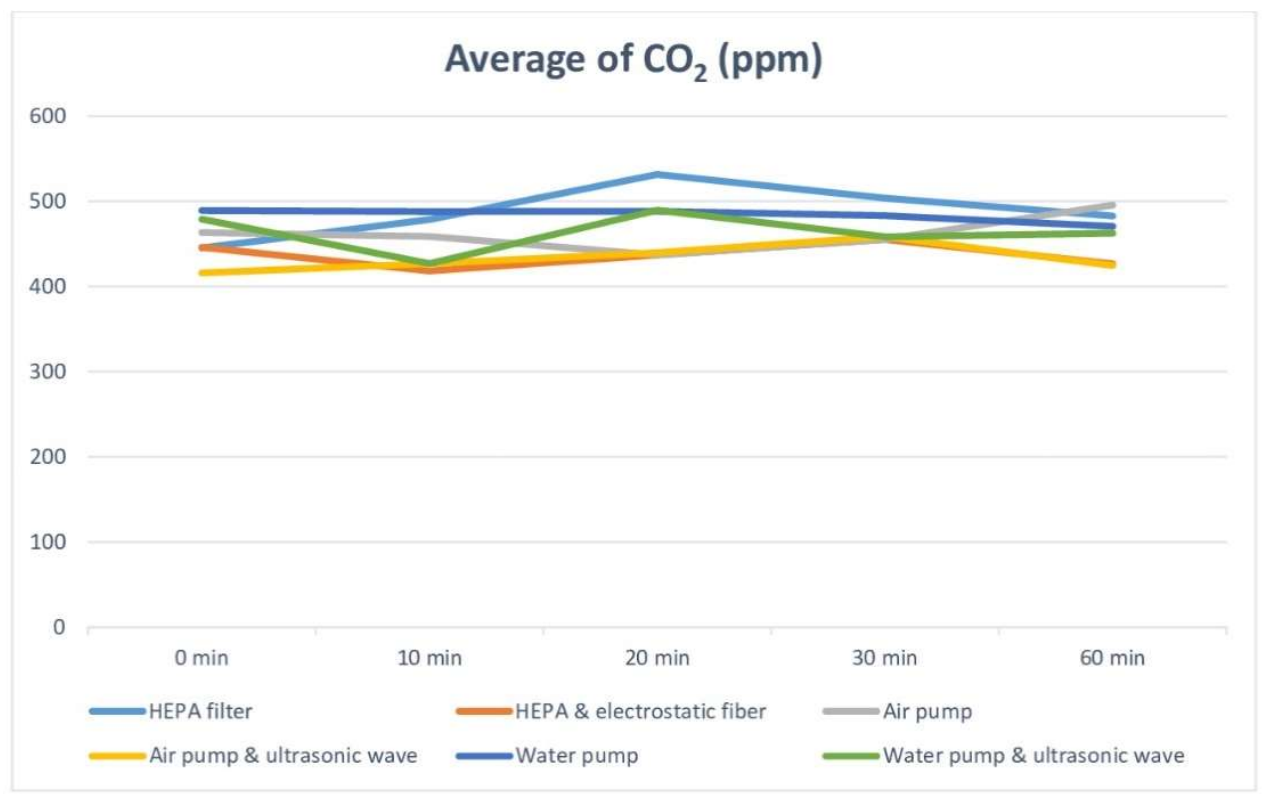

Figure 7. The average $\mathrm{CO}_{2}$ levels (ppm) at different times 


\subsection{Cost-effective analysis}

The cost of inventories, which were calculated in Thai Baht (THB), are shown in Table 4. A product's service life for each prototype was set at 3 years. Initial cost consisted of the standard wages $200 \mathrm{THB}$ and equipment costs, including, a ventilating fan with its accessories 1,000 THB, an air pump with its accessories 1,120 THB, a water pump with its accessories $460 \mathrm{THB}$, and an aquarium mist maker $300 \mathrm{THB}$, respectively.

Maintenance expenses per month for each prototype also included the wages $10 \mathrm{THB}$ and the replacement parts as follows; HEPA filter 1,000 THB and electrostatic fiber $400 \mathrm{THB}$ (if any) for HEPA filter methods, and water 10 THB per $10 \mathrm{~L}$ with a polyurethane sponge 40 THB (annual replacement) for each water-based air purifier system, respectively.

The electricity charge was analyzed at the rate of 2.3488 THB for 1 kilowatt-hour when all prototypes worked 8 hours per day and for 30 days per month, respectively. Being part of the electrical devices, the costs of an $8 \mathrm{~W}$ ventilating fan, $25 \mathrm{~W}$ air pump, $25 \mathrm{~W}$ submersible pump, and also a $25 \mathrm{~W}$ mist maker, were calculated.

The results showed HEPA filter \& electrostatic fiber technique needed the highest maintenance rate, followed by the HEPA filter method, and water-based purifier systems, which correlated with the total cost in 3 years. A water pump procedure was the cheapest air cleaner method, working for over 3 years, followed by an air pump method.

Table 4. Comparison of costs among any air purifier prototypes

\section{Cost (Thai baht, THB)}

\begin{tabular}{|c|c|c|c|c|c|}
\hline \multirow{2}{*}{ Prototype } & \multirow{2}{*}{$\begin{array}{c}\text { Initial } \\
\text { cost }\end{array}$} & \multicolumn{3}{|c|}{ Variable cost per year } & \multirow{2}{*}{$\begin{array}{l}\text { Total cost } \\
\text { in } 3 \text { years }\end{array}$} \\
\hline & & $\begin{array}{c}\text { Maintenance } \\
\text { expenses }\end{array}$ & $\begin{array}{c}\text { Electricity } \\
\text { charge }\end{array}$ & Total & \\
\hline \multirow{2}{*}{$\begin{array}{l}\text { HEPA filter } \\
\text { HEPA \& electrostatic } \\
\text { fiber }\end{array}$} & $1,200.00$ & $12,120.00$ & 54.00 & $13,374.00$ & $37,722.00$ \\
\hline & $1,200.00$ & $16,920.00$ & 54.00 & $18,174.00$ & $52,122.00$ \\
\hline \multirow{2}{*}{$\begin{array}{l}\text { Air pump } \\
\text { Air pump \& ultrasonic } \\
\text { wave }\end{array}$} & $1,320.00$ & 280.00 & 169.08 & $1,769.08$ & $2,667.24$ \\
\hline & $1,620.00$ & 280.00 & 338.28 & $2,238.28$ & $3,474.84$ \\
\hline \multirow{2}{*}{$\begin{array}{l}\text { Water pump } \\
\text { Water pump \& } \\
\text { ultrasonic wave }\end{array}$} & 660.00 & 280.00 & 169.08 & $1,109.08$ & $2,007.24$ \\
\hline & 960.00 & 280.00 & 338.28 & $1,538.28$ & $2,774.84$ \\
\hline
\end{tabular}




\section{Discussion}

A HEPA filter \& electrostatic fiber prototype is the best way to reduce the levels of particulate matter, nonetheless, this method also released a heavy amount of returned dust. This phenomenon may occur according to the filtrate materials, which were made of PP fiber, having good properties to prevent dust entry at the end of the airway, but also poor dust absorption properties. To promote filtration efficiency, a low-cost DIY air purifier using a ventilating fan should be incorporated with an air reserve at the entrance of the airway prior to the dust passing through either an electrostatic fiber or HEPA filter. When switching off the air purifier the user must close the air entry immediately to prevent backflow of dust particles. The fabrication of the HEPA filter-based air cleaner without an air reservoir at the entry part is therefore not recommended. Comparison of dust prevention, as well as cost-effectiveness, between the HEPA filter method and HEPA filter \& electrostatic fiber method, is similar. To maintain an air purifier efficiency of more than $90 \%$, the HEPA filter \& electrostatic fiber technique is minimally better than HEPA filter on its own. However, the maintenance cost of these products will be an issue.

Regarding the water-based air cleaner systems, an air pump technique provides the best highefficiency system that can reduce air pollution at a low cost. However, humidity became a significant factor that could interfere with the experiments. The accumulation of vapor within the PVC boxes of all water-based air purifier experiments was strikingly increased but did not appear at the boxes of HEPA filter-based prototypes. After $30 \mathrm{~min}$ of air treatment, the presence of high humidity interfered with the measurement of air pollution. To reduce the interference of humidity, the addition of a ventilating fan after an air treatment is an appropriate choice, but also this solution is not necessary if we need to return the humidity to the environment. To ensure that the false positive readings of particulate matter levels were a result of vapor present within the system, humidity measurement should be prioritized in the next investigation. Other water-based air purifiers, including, a water pump, air pump \& ultrasonic wave, also a water pump \& ultrasonic wave, revealed fluctuation of particulate matter levels. Even though the author put an ultrasonic generator beneath a polyurethane sponge to prevent a false positive measurement of PM linked to the emergence of the mist, the results were not positive. Therefore, such an ultrasonic wave technique should not be amalgamated with similar water-based air purifier systems. This phenomenon hypothesized that evaporating water had attached to the inner side of the PVC box, where there was a temperature gradient between the inner and outer box, and then it condensed and became visible water. Therefore, the pulsatile graph of particulate matter coincided with the rhythm of condensation [21,22]. Regarding $\mathrm{CO}_{2}$ levels, all DIY air cleaner prototypes from this study are not suitable for the reduction of $\mathrm{CO}_{2}$.

\section{Conclusions}

In this research paper, the author has focused on alternative ways to protect people in low- and middle-income countries from the air pollution crisis. Six low-cost DIY air purifier prototypes were fabricated and tested. At $60 \mathrm{~min}$ of air treatment, the results showed that a HEPA filter amalgamated with an electrostatic fiber prototype had the highest PM reducing efficiency, followed by HEPA filter on its own, and then an air pump technique, respectively. However, the best performance measured occurred at $30 \mathrm{~min}$ of air treatment using an air pump technique. Both 
air purifiers using a ventilating fan released dust when switched off following an air treatment process. All experiments showed fluctuation of $\mathrm{CO}_{2}$ levels with the result that all the DIY techniques used in this study are not useful for $\mathrm{CO}_{2}$ management.

In summary, the most appropriate air cleaner prototype depends on usability. The optimum method, which can reduce both particulate matter and cost, without the consideration of humidity, is an air pump technique. The HEPA filter \& electrostatic fiber method is the best choice to decrease PM levels without an increase in humidity and production of vapor, but also it needs an enclosed structure at the air inlet to prevent dust coming back into the room. Of relevance is the reality that the filtration efficiency of filter \& electrostatic fiber procedures, is likely unaffordable for the target population. The author hopes that knowledge from this research can be implemented to help people to make a low-cost air purifier on an individual basis to protect us away from the haze crisis and also the spread of COVID-19. In the future, when the prototype is stable, the internet of things (IoT) technology and a smartphone should be applied for the next products.

\section{Conflict of Interest}

The author has no conflict of interest to declare.

\section{Author Contributions}

Arnon Jumlongkul created all experiments, analyzed, and drafted the manuscript solely.

\section{Funding}

This work was supported by the Haze-free Thailand Fund, Mae Fah Luang University, Memorandum No. 7742(1)/0646, the fiscal year 2020.

\section{Acknowledgments}

The author would like to thank Dr. Roger Timothy Callaghan MB. ChB. a lecturer at the School of Medicine for grammatical approval, Sitang Kongkratoke, a lecturer at the School of Health Science, and also Watchara Jamnuch, an electrical engineer, for technical support. The declaration of conflict of interest is none.

\section{References}

1. World Health Organization. Air pollution [Internet]. 2020 [cited 2020 Aug 21]. Available from: https:/www.who.int/airpollution/ambient/health-impacts/en/

2. Butt EW, Turnock ST, Rigby R, Reddington CL, Yoshioka M, Johnson JS, et al. Global and regional trends in particulate air pollution and attributable health burden over the past 50 years. Environ Res Lett. 2017 Oct 1;12(10):104017.

3. Pardthaisong L, Sin-ampol P, Suwanprasit C, Charoenpanyanet A. Haze Pollution in Chiang Mai, Thailand: A Road to Resilience. Procedia Eng. 2018;212:85-92.

4. Phetpradap P. A Fuzzy Soft Model for Haze Pollution Management in Northern Thailand. Adv Fuzzy Syst. 2020 Mar 11;2020:1-13. 
5. Hamanaka RB, Mutlu GM. Particulate Matter Air Pollution: Effects on the Cardiovascular System. Front Endocrinol [Internet]. 2018 Nov 16 [cited 2020 Aug 22];9. Available from: https://www.frontiersin.org/article/10.3389/fendo.2018.00680/full

6. Crinnion W. Particulate Matter Is a Surprisingly Common Contributor to Disease. Integr Med Encinitas Calif. 2017 Aug;16(4):8-12.

7. Fennelly KP. Particle sizes of infectious aerosols: implications for infection control. Lancet Respir Med. 2020 Sep;8(9):914-24.

8. Vijayan V, Paramesh H, Salvi S, Dalal AK. Enhancing indoor air quality - The air filter advantage. Lung India. 2015;32(5):473.

9. Peck RL, Grinshpun SA, Yermakov M, Rao MB, Kim J, Reponen T. Efficiency of portable HEPA air purifiers against traffic related combustion particles. Build Environ. 2016 Mar;98:21-9.

10. Fermo P, Comite V, Falciola L, Guglielmi V, Miani A. Efficiency of an Air Cleaner Device in Reducing Aerosol Particulate Matter (PM) in Indoor Environments. Int J Environ Res Public Health. 2019 Dec 18;17(1):18.

11. Shi B, Ekberg L. Ionizer Assisted Air Filtration for Collection of Submicron and Ultrafine Particles-Evaluation of Long-Term Performance and Influencing Factors. Environ Sci Technol. 2015 Jun 2;49(11):6891-8.

12. Sandle T. Sterility, sterilisation and sterility assurance for pharmaceuticals: technology, validation and current regulations. Oxford [u.a.] Woodhead Publ; 2013. 339 p. (Woodhead Publishing series in biomedicine).

13. Zhang H, Liu J, Zhang X, Huang C, Jin X. Design of electret polypropylene melt blown air filtration material containing nucleating agent for effective PM2.5 capture. RSC Adv. 2018;8(15):7932-41.

14. Lou C-W, Shih Y-H, Huang C-H, Lee S-A, Chen Y-S, Lin J-H. Filtration Efficiency of Electret Air Filters Reinforced by Titanium Dioxide. Appl Sci. 2020 Apr 13;10(8):2686.

15. Nadooshan AA, Shirani E. Numerical Simulation Of A Single Air Bubble Rising In Water With Various Models Of Surface Tension Force. Int J Aerosp Mech Eng. 2008 Mar 29;2(1):43-7.

16. Pradeep A, Sharma AK, Rajiniganth MP, Malathi N, Sivaramakrishna M, Ponraju D, et al. NUMERICAL AND EXPERIMENTAL INVESTIGATION OF AIR-WATER SYSTEM TO SIMULATE BUBBLE DYNAMICS IN LIQUID SODIUM POOL. Braz J Chem Eng. 2019 Dec;36(4):1475-85.

17. Karakashev SI, Grozdanova MV. Foams and antifoams. Adv Colloid Interface Sci. 2012 Aug;176-177:1-17. 
18. Ganas DE. Performance Analysis of a Venturi Water Pump With Different Parts Variation. Int J Res Appl Sci Eng Technol. 2017 Nov 13;V(XI):163-8.

19. Zhou D, Luo Z, Fang M, Xu H, Jiang J, Ning Y, et al. Preliminary Experimental Study of Acoustic Agglomeration of Coal-fired Fine Particles. Procedia Eng. 2015;102:1261-70.

20. Jian-yong L, Dong L, Zhe Z, Wen-li D. Progress in Research and Application of Electronic Ultrasonic Water Mist Fire Suppression Technology. Procedia Eng. 2011;11:288-95.

21. Lindblom J, Nordell B. Water production by underground condensation of humid air. Desalination. 2006 Mar;189(1-3):248-60.

22. LeiLei Z, XueZhi F. Study on Mechanism of Water Condensation and Field Experiments of Thousand-Hand Guanyin in Dazu Rock Carvings. IOP Conf Ser Earth Environ Sci. 2018 Oct 11;186:012007. 